See discussions, stats, and author profiles for this publication at: https://www.researchgate.net/publication/340612557

Corrosion Performance and Wear Behaviour of AA6061 Reinforced Hybrid: Nano-Rice Husk Ash/Clay Particulate for Cooling Tower Fan Blade in 0.75 M $\mathrm{H} 2 \mathrm{SO} 4$

Article in Journal of Bio- and Tribo-Corrosion · April 2020

DOI: $10.1007 / 540735-020-00359-6$

CITATIONS

0

3 authors:

Nduka Udoye

Covenant University Ota Ogun State, Nigeria

32 PUBLICATIONS 66 CITATIONS

SEE PROFILE

Ojo Sunday Isaac Fayomi

Bells University of Technology

434 PUBLICATIONS 2,150 CITATIONS

SEE PROFILE

Some of the authors of this publication are also working on these related projects:

Artificial Neural Network Applications View project

MATERIAL/MINERALOGY PROJECT View project
READS

84

A. O. Inegbenebor

Covenant University Ota Ogun State, Nigeria

68 PUBLICATIONS 264 CITATIONS

SEE PROFILE 


\title{
Corrosion Performance and Wear Behaviour of AA6061 Reinforced Hybrid: Nano-Rice Husk Ash/Clay Particulate for Cooling Tower Fan Blade in $0.75 \mathrm{M} \mathrm{H}_{2} \mathrm{SO}_{4}$
}

\author{
N. E. Udoye ${ }^{1} \cdot$ A. O. Inegbenebor ${ }^{1}$ - O. S. I. Fayomi ${ }^{1,2}$
}

Received: 4 November 2019 / Revised: 30 March 2020 / Accepted: 2 April 2020

(c) Springer Nature Switzerland AG 2020

\begin{abstract}
The failures of material performance in industry are due to structural, corrosion and wear dilapidation in service. This study attempts to develop AA6061 with rice husk ash and clay hybrid to address this phenomenon for application in cooling tower fan blade. This study also targets at developing sustainable and long-lasting hybrid of aluminium biodegradable composites through metallurgical stir casting techniques. Corrosion properties were examined using Potentiostat Galvanostat (PGStat 101) with Nova software acquisition while pin-on-disc wear machine was used to analyse the wear propagation of the composites. The microstructure, chemical composition and quantification were examined with SEM/EDS. It was established that the reinforcement improved corrosion susceptibility of the composites in $0.75 \mathrm{M} \mathrm{H}_{2} \mathrm{SO}_{4}$ solution. The coefficient of friction and the wear resistance of the hybrid composites were better than the as-received sample. Furthermore, AA6061/8\% rice husk ash + clay at $75 \mu \mathrm{m}$ possesses rod-like pattern and unique structure grain crystal.
\end{abstract}

Keywords Aluminium alloy $\cdot$ Particulate $\cdot$ Mechanical properties $\cdot$ Rice husk ash $\cdot$ Clay $\cdot$ Stir casting

\section{Introduction}

The development of biodegradable agro-waste reinforcing materials on aluminium based alloys in comparison with ceramic materials is of high demand in the industry $[1,2]$. Studies have shown that metal matrix composites (MMCs) materials are in urgent demand world-wide due to their light weight, super functionality and corrosion susceptibility in service [3]. The need to produce inexpensive materials, especially MMCs with improved characteristics, has been in the mind of numerous scientists [4, 5]. Aluminium hybrid reinforcement technology proffers solution to the vigorous quest for services especially in aerospace and automobile. Hybrid aluminium alloy is the mixture of two or more materials with disparities in composition and

N. E. Udoye

nduka.udoye@covenantuniversity.edu.ng

1 Department of Mechanical Engineering, College of Engineering, Covenant University Ota, Ota, Ogun State, Nigeria

2 Department of Chemical, Metallurgical and Materials Engineering, Tshwane University of Technology, Private Bag X680, Pretoria 0001, South Africa showing properties characteristically different from other separate materials of the same alloy [6]. Challenges arising from corrosion threats cause malfunctioning of plants, wastage of materials, inefficiency in operation and exorbitant repairs. This also threatens safety and prevents advancement in technology innovations [7]. Corrosion complications in the manufacturing industry occur at the entire phases from interior to the surface equipment leading to persistent plant shut down which causes huge financial losses to the industry. The anticipated form of corrosion depends on many factors including the corrosivity of the neighbouring environment [8]. Corrosion effects can be ameliorated through identification and comprehension of corrosion devices by the use of corrosion-resistant materials and system protection. The impact of corrosion disasters on the effective operation and material maintenance would reduce if adequate observation and regulation of the environments and human capabilities support proficient designs [9]. The need to create economically attractive composite has brought about several invention in manufacturing procedures to be utilized in the industry. Among the numerous additives used such as $\mathrm{SiC}, \mathrm{Al}_{2} \mathrm{O}_{3}$, and so on, rice husk ash (RHA) and clay are the cheapest reinforcing agents obtainable in large number as agro- and industrial waste by-product. In the present study, effort is 
made to utilize RHA and clay as reinforcement in MMCs to improve the corrosion and wear behaviour of the material. [10] used Kankara mud (alumino-silicate) to strengthen Al-Si alloy. The author affirmed that inclusion of aluminosilicate in the alloy causes increment in hardness values; however, it decreases the impact energy and porosity. Reinforcing aluminium with $20 \%$ wt. alumina-silicate resulted to increase in compressive strength. Macro-structural studies showed a good homogenous dispersal of alumino-silicate particles. However, there are bit macro-separations of particulates in some areas due to secondary grains. [2] investigated the mechanical properties of AA356.2 alloy reinforced with rice husk ash particles. It was found that the production and analysis of AA356.2 alloy/rice husk ash composites show more desired microstructure and mechanical characteristics than unreinforced aluminium alloy. The result of the analysis show that inclusion of rice husk ash particulate in aluminium matrix leads to the manufacturing of cheaper aluminium composites with enhanced hardness and strength which can be applied in automobile industry. [11] carried out reinforcement of aluminium alloy using kaolinite and carbon to produce hybrid metal matrix composites. It was noted that properties of chilled MMCs are superior to unreinforced matrix alloy. Increasing the kaolinite $\left(\mathrm{Al}_{2} \mathrm{SiO}_{5}\right)$ content increased the strength, hardness and wear resistance of the developed composites. According to [12], "The failure of one blade also damage other blades, drive shaft and other components and hence causes huge financial impact as well as fan availability". The result of the experiments shows that fan blade failure was due to excessive deflection caused by crack initiation at its root. The hitting of other deflected blade with other fan components such as drive shaft and failure of any one blade becomes primary reason of failure of other fan components. The analysis of failed blade by visual inspection and finite element analysis shown that the blade is failing repeatedly at mainly two points: one at its shank/neck portion and second near $1 / 3$ of the blade length from its tip side [13].

The research problems formulated are the structural deformation of plastic fan blade components due to environmental assisted failure distorting the grain boundaries. Secondly, the corrosive environment emanating from the cooling tower contains ions of sulphide, hydroxide and chloride leading to pitting which reduce component life span. The novelty of the research work is to provide alternate solution to repeated material failure by consistently minimizing undue cost incurred and life challenges caused by corrosion dilapidation during application. To improve on the use of agro-waste aluminium metal matrix alloy for cooling tower fan blade in textile industries with high durability. The main reason of using $\mathrm{H}_{2} \mathrm{SO}_{4}$ as the test solution is because the chemical for the production of textile consists of $\mathrm{H}_{2} \mathrm{SO}_{4}$ which comes in contact with the cooling tower fan blade; therefore, we simulate the environment.

The aim of the study were as follows: to reinforce AA6061 with rice husk ash and clay to improve the mechanical properties such as hardness and tensile strength to address the incessant cases of failure of cooling tower fan blade in textile industry, and it also targets at developing sustainable and long-lasting hybrid of aluminium biodegradable composites through metallurgical stir casting techniques; and, furthermore, to study the corrosion and wear behaviour of the developed composites.

\section{Materials and Methods}

\subsection{Matrix Material}

The starting materials are high grades of AA6061 Al-alloy due to their structural properties. These materials were selected because of the inherent properties and high strength they exhibited. AA6061 consists of magnesium and silicon as its major alloying element and better mechanical properties. Other properties include allowing complicated shapes to be developed with very neat surfaces, heat treatable and weldable. The chemical composition of matrix is shown in Table 1.

\subsection{Formation of AA6061/RHA + Clay Composite by Stir Casting Techniques}

Figure 1 shows the stir casting set-up for the experiment. A uniform dispersal of RHA and clay in the AA6061 aluminium alloy was performed by dissolving AA6061 ingots in the furnace and adding the $75 \mu \mathrm{m}$ and $150 \mu \mathrm{m}$ particulate in the molten matrix formed by a stirrer, turning at a regular speed in the crucible. The molten form of AA6061 alloy with rice husk ash and clay was transported and solidified in the die cast. The dispersal of the RHA and clay in the melted AA6061matrix is a function of the position of the mechanical stirrer and temperature [14]. The production of MMCs used in the present study is performed successfully by using metallurgical stir casting techniques. The fabrication of AA6061/RHA + clay composite involves molten matrix, mixing of the reinforcement and casting of the composite.
Table 1 Chemical composition of AA6061 (wt\%)

\begin{tabular}{lllllllll}
\hline Element & $\mathrm{Al}$ & $\mathrm{Mg}$ & $\mathrm{Si}$ & $\mathrm{Fe}$ & $\mathrm{Cu}$ & $\mathrm{Zn}$ & $\mathrm{Mn}$ & $\mathrm{O}$ \\
\hline Composition & 85.0 & 3.3 & 2.25 & 2.13 & 1.5 & 0.25 & 0.12 & 5.0 \\
\hline
\end{tabular}




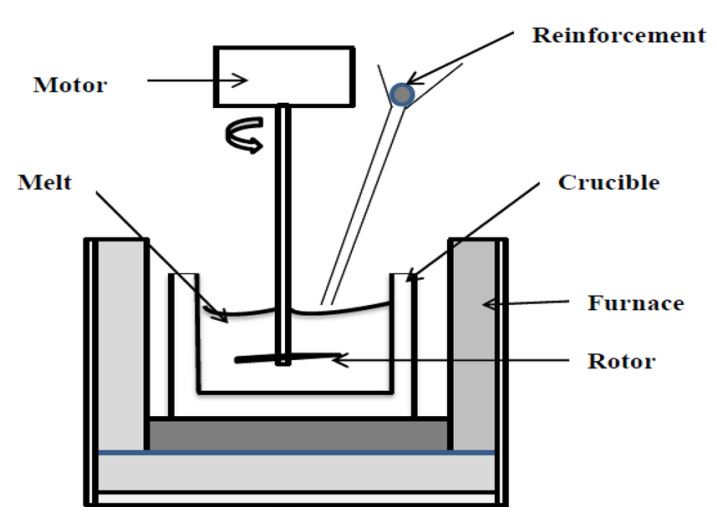

Fig. 1 Stir casting techniques

A $3 \mathrm{~kg}$ of AA6061 ingots was poured into the graphite crucible positioned in the stir cast set-up at different percentage variation of $92 \%$ and $98 \%$ for additive addition, respectively. AA6061 matrix alloy was stirred continuously through the mechanical stirrer at $450 \mathrm{rpm}$ for $10 \mathrm{~min}$, and a vortex was produced in the crucible position in the furnace. The grain size of $75 \mu \mathrm{m}$ and $150 \mu \mathrm{m}$ RHA + clay particulate was added in the range of $2 \%$ and $8 \%$ weight percentage to the melted AA6061 alloy at the vortex, and melted composite of varying proportions of AA6061/RHA + clay was prepared. The molten composite was then transferred to a metallic die cast of dimension $250 \mathrm{~mm} \times 25 \mathrm{~mm}$ size cylindrical hole instantly at a pouring temperature of $680^{\circ} \mathrm{C}$.

\subsection{Characterization of the Composite Samples}

The microstructural study of the developed alloy was examined using SEM/EDS after proper metallographic analysis with $0.1 \mathrm{M} \mathrm{HCl}$. Potentiodynamic polarization technique was used to characterize the corrosion behaviour of the samples. AUTOLAB Potentiostat Galvanostat (PGStat 101) with Nova software acquisition was utilized to analyse the corrosion characteristics of control sample and that of the reinforced material in $0.75 \mathrm{M} \mathrm{H}_{2} \mathrm{SO}_{4}$ solution. The alloys were scan with $0.02 \mathrm{v}$ and potential difference of $-1.5 \mathrm{v}$ to $+1.5 \mathrm{v}$. The polarization curves were plotted with the use of the Autolab data acquisition system and the rate of corrosion and potential was gotten by extrapolation.

The wear behaviour was performed for starting material and the reinforced aluminium alloy using pin-on-disc method in a dry sliding wear test at room temperature under varying applied load of $7.5 \mathrm{~N}$ and $10 \mathrm{~N}$ with a constant sliding velocity of $0.32 \mathrm{~m} / \mathrm{s}$ for 15 minutes. The cylindrical pins were machined from the composite material with the dimensions of $8 \mathrm{~mm}$ diameter and $40 \mathrm{~mm}$ in length. The Pin-on-disc wear set-up is shown in Fig. 2. With the test process, the specimens (ball and sample) moved relative to one another in a linear back and forth sliding motion. The

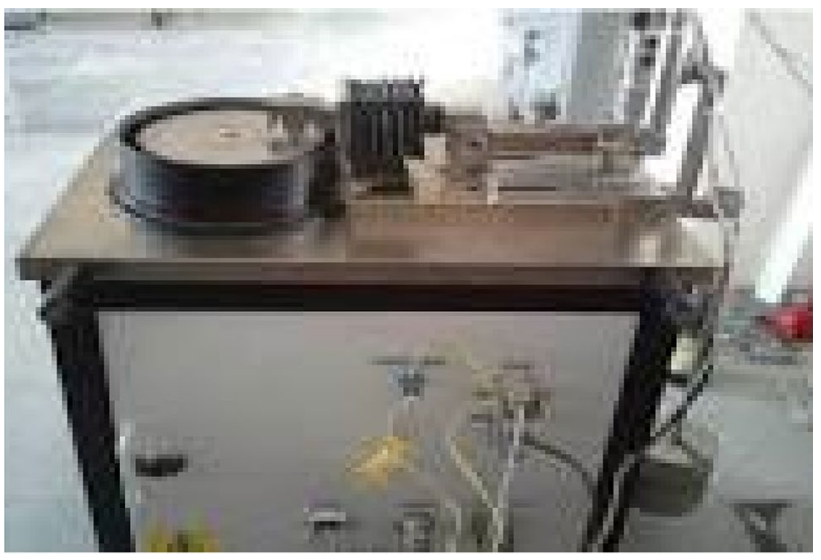

Fig. 2 Pin-on-disc wear testing machine

upper specimen was motorized by a vertical positioning system with another position encoder. The pin-on-disc was performed under $25^{\circ} \mathrm{C}$, relative humidity of about $50 \%$, with unlubricated ambient atmospheric condition.

\section{Results and Discussion}

\subsection{SEM/EDS Analyses of AA6061/Rice Husk Ash + Clay Reinforcement}

Figure 3 shows the surface morphology and EDS for Asreceived aluminium alloy. Figure 4a shows the microstructure of the produced AA6061/RHA + clay composite prepared by stir casting techniques. It shows accumulation of distributed grains and dense crystalline structure in comparison with as-received sample. The effect of combined particulate of rice husk and clay kaolinite is presented in Fig. 4b. It is interesting to see a nodular particle with better refined crystal due to the enhanced orientation of the additive with the compositional constituent of all essential aggregates seen at the EDS. It is worth noting that the variation of quantity of additives plays a predominant role in the stable modification of crystal. This effective compact tri-phase ceramic and composite formed that is precipitated forming primary $\beta^{\prime \prime}-\mathrm{Al}$ lattices and active metallic grain structural revolution. In this work, established fact from [15] has situated that potential ceramic particulates have tendency to cause homogenous build-up due to the nucleation mechanism thereby forming a robust solid diffusion within aluminium lattice seen in Fig. 4b. The inclusion of hybrid reinforcement led to the creation of silica-rich layer at the matrix boundary as discussed by [16]. Figure 5a shows the SEM/EDS microstructure of the produced AA6061/2\%RHA + Clay composite at $150 \mu \mathrm{m}$. It shows that the structure consists of distributed crystallites of various compactible dimensions. Furthermore, 
Fig. 3 SEM/EDS spectra for asreceived aluminium alloy
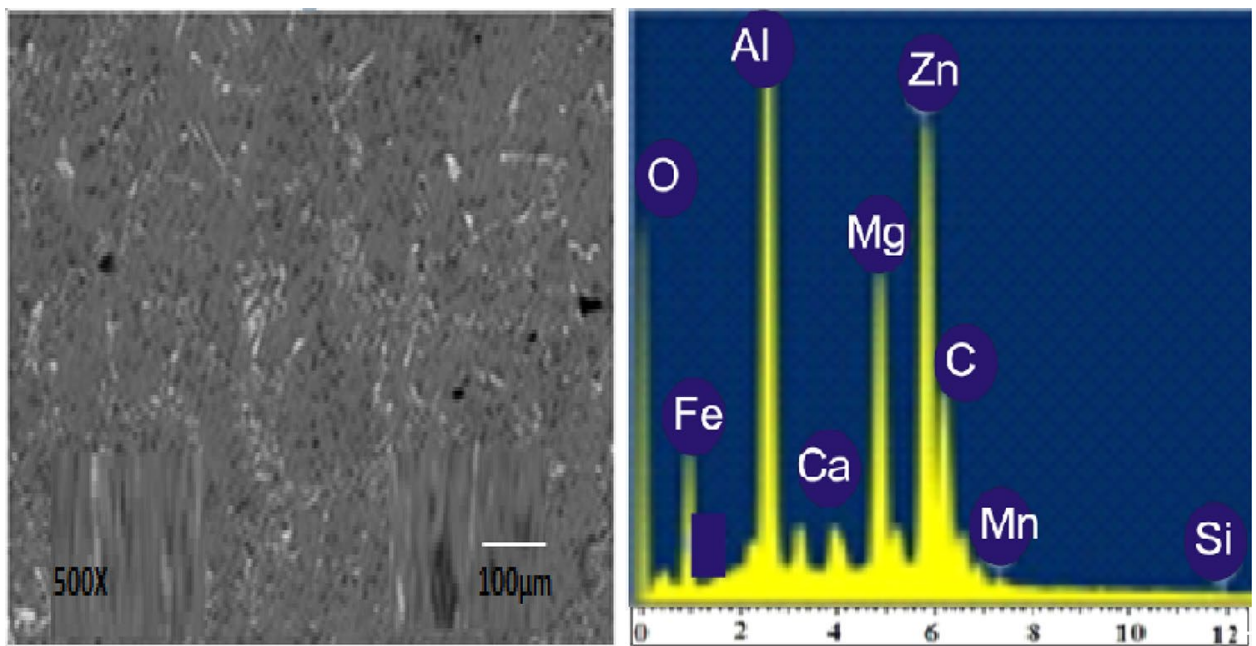

Fig. 4 a SEM/EDS of AA6061/2\% RHA + clay at $75 \mu \mathrm{m}$. b SEM/EDS of AA6061/8\% clay + RHA at $75 \mu \mathrm{m}$
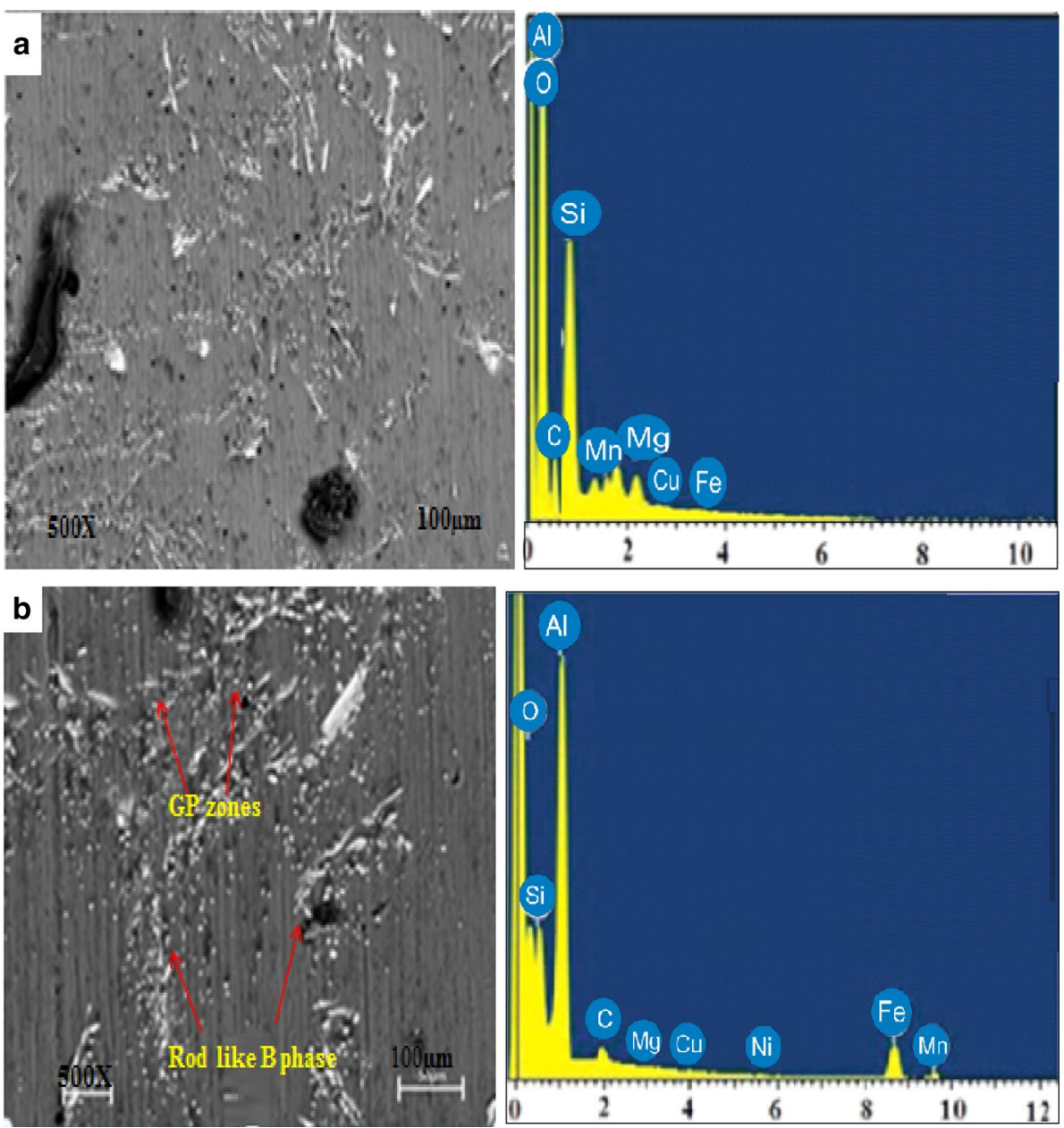

morphological structure is observed to adhere strictly with aluminium silicate in the matrix. Figure 5b shows the SEM/ EDS microstructure of the produced AA6061/8\%RHA + clay composite at $150 \mu \mathrm{m}$. It shows a free porous characteristic with the EDS revealing the existence of aluminium silicate distribution within the aluminium matrix boundary. The EDS analysis was carried out on the hybrid composite to obtain the compositional constituents of the reinforced aluminium alloy. The EDS of the starting material reveals the predominance of aluminium in the alloy and elements 
Fig. 5 a SEM/EDS of AA6061/2\% clay + RHA at 150 . b SEM/EDS of AA6061/8\% clay + RHA at $150 \mu \mathrm{m}$
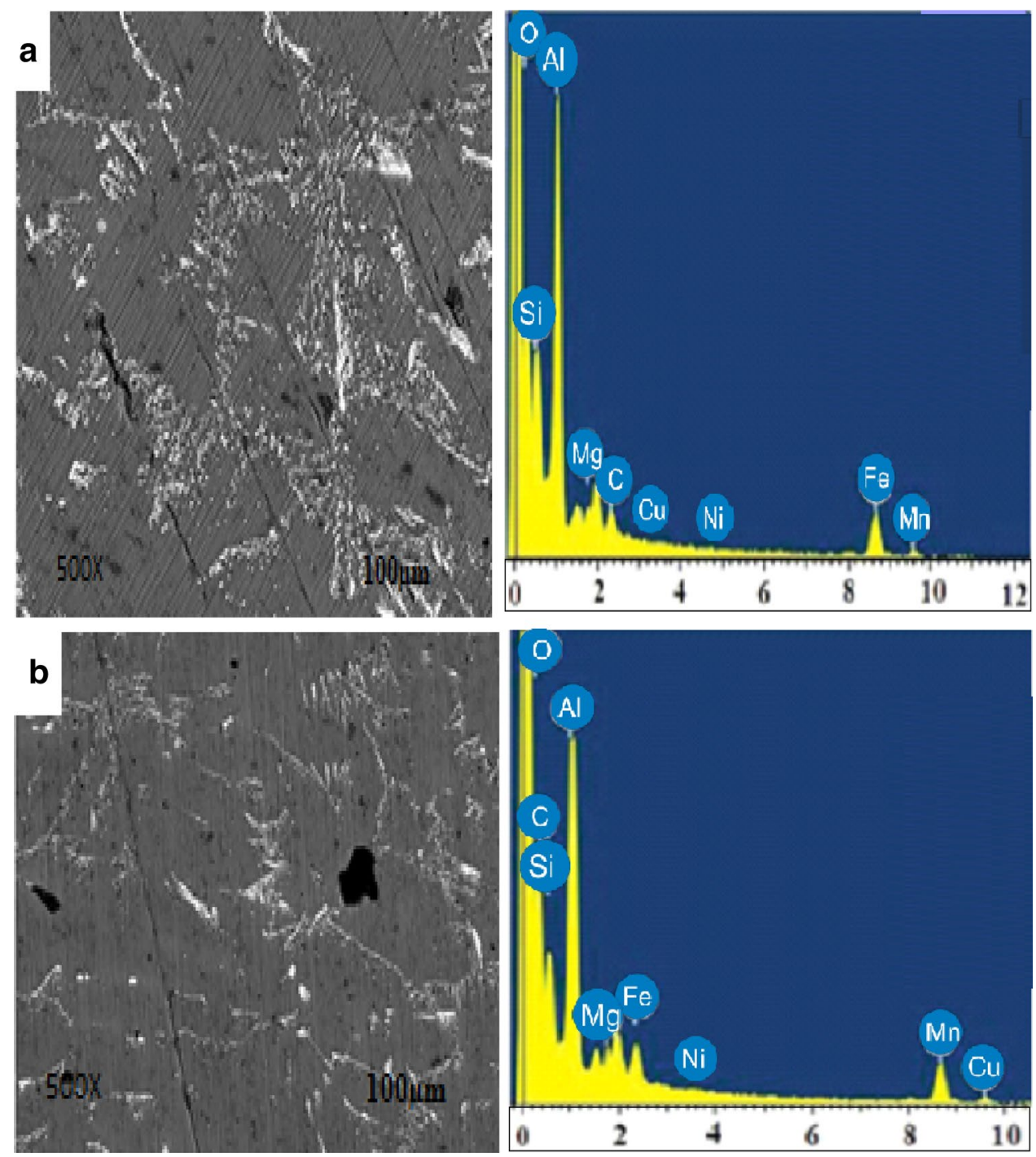

magnesium, calcium, iron and silicon in small quantity as shown in Fig. 3. The EDS profile Fig. 4b shows the peak of silicon, calcium, iron and magnesium at the interface which are constituents derived from the particulates used.

Figure 6 shows the SEM after wear for as-received aluminium alloy. The worn surfaces are analysed using SEM to comprehend the wear mechanism that occurred during the wear process. Figures $7 \mathrm{a}, \mathrm{b}$ and $8 \mathrm{a}, \mathrm{b}$ show the SEM after wear at different percentage composition of RHA + clay at $75 \mu \mathrm{m}$ and $150 \mu \mathrm{m}$, respectively, at constant sliding velocity of $0.32 \mathrm{~m} / \mathrm{s}$ and sliding distance of $40 \mathrm{~m}$. Figure $7 \mathrm{~b}$ shows regions of wear flakes where wear debris is significantly fine and flake size is noticeably smaller due to the lubricating effect of clay/rice husk ash particles. Furthermore, it can be concluded that the leading wear mechanism in the reinforced and unreinforced alloy is obvious which turns to shallow wear pattern in AA6061/8\%RHA + clay composite at $75 \mu \mathrm{m}$. The shallow wear mechanism identified in Fig. 7b shows it as the best wear performance. The improvements in wear

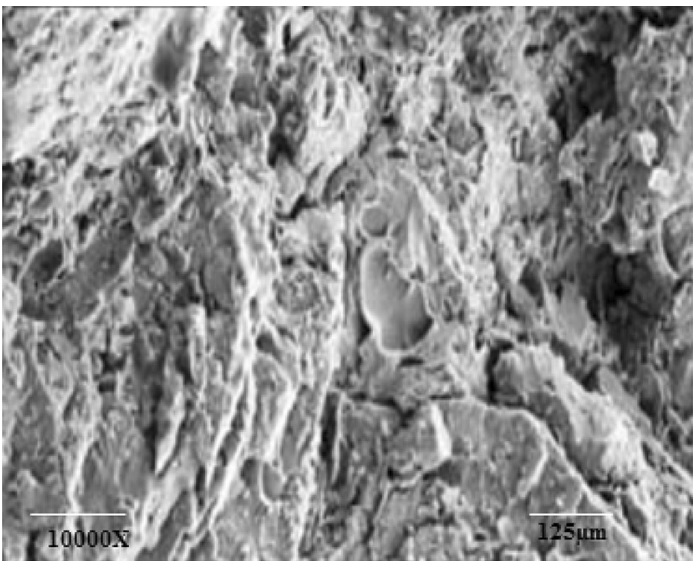

Fig. 6 SEM after wear for as-received aluminium alloy

resistance and the lowest friction coefficient of the hybrid composites are attributed to the solid lubrication effect 
Fig. 7 SEM after wear of: a AA $6061 / 2 \%$ clay + RHA at $75 \mu \mathrm{m}$ b AA6061/8\% RHA + clay at $75 \mu \mathrm{m}$
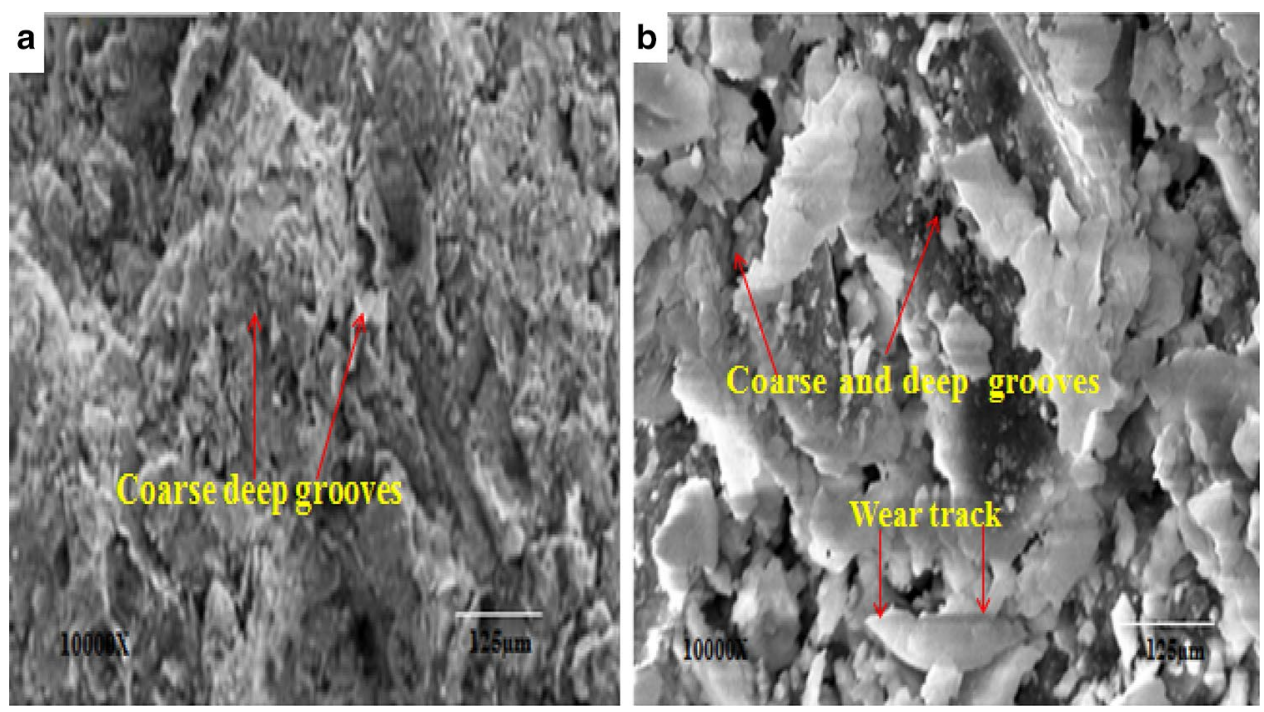

Fig. 8 a AA6061/2\%

RHA + clay at $150 \mu \mathrm{m} \mathbf{b}$ AA6061/8\% clay/RHA at $150 \mu \mathrm{m}$
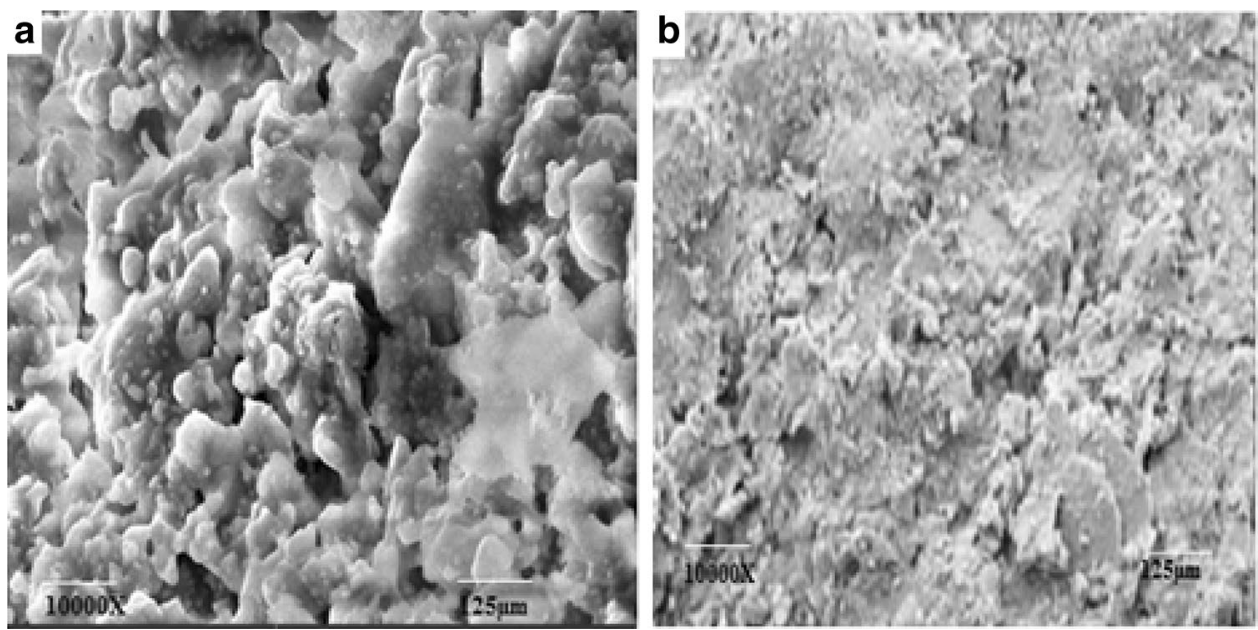

provided by rice husk and clay particles. During sliding wear test, reinforcing particles such as clay and rice husk ash changed the structure of wear debris and wear mechanism. Microstructure of the wear debris and flakes also changed in the similar manner from larger and irregular ones to much finer and smaller ones in hybrid composite, respectively.

\subsection{Open-Circuit Potential (OCP) Measurements}

Figure 9 shows the OCP versus time plots for unreinforced and reinforced AA6061/RHA + clay composite in $0.75 \mathrm{M}$ $\mathrm{H}_{2} \mathrm{SO}_{4}$ solution. The near straight or near unity of the lines indicate that stabilized state or steady-state potential was achieved [17]. It shows that steady-state potential was achieved and that the shift of the Eocp of the reinforced alloy to the more negative sides with respect to the unreinforced Eocp further confirmed the predominant cathodic protecting nature of the AA6061/RHA + clay composite reinforcements. It is also seen that the potential of the AA6061/8\%
RHA + clay at $75 \mu \mathrm{m}$ increased towards the more negative values from the first moment of electrode immersion as a result of the dissolution of an air oxide film formed on the electrode before its immersion in the solution.

\subsection{Wear Behaviour AA6061/RHA + Clay}

Figure 10 shows the wear rate of hybrid composite with applied load across the reinforced system of AA6061/ RHA + clay at $75 \mu \mathrm{m}$ and $150 \mu \mathrm{m}$ fabricated composite. From the results, the pattern of wear rate steadily improved with increase in applied loads. It is observed that wear rate of reinforced hybrid composite is lower than the unreinforced AA6061 aluminium alloy. The presence of hybrid reinforcements (rice husk ash and clay) in the $\mathrm{Al}$ matrix limits the plastic deformation at initial loading conditions at $7.5 \mathrm{~N}$ and allows the plastic to deform slightly. The wear increases for some composites especially unreinforced alloy because of the absence of additives which improve the wear 
Fig. 9 OCP variation with time for AA6061/RHA + clay composite in $0.75 \mathrm{M} \mathrm{H}_{2} \mathrm{SO}_{4}$ environment
Fig. 10 Graph of wear rate with load

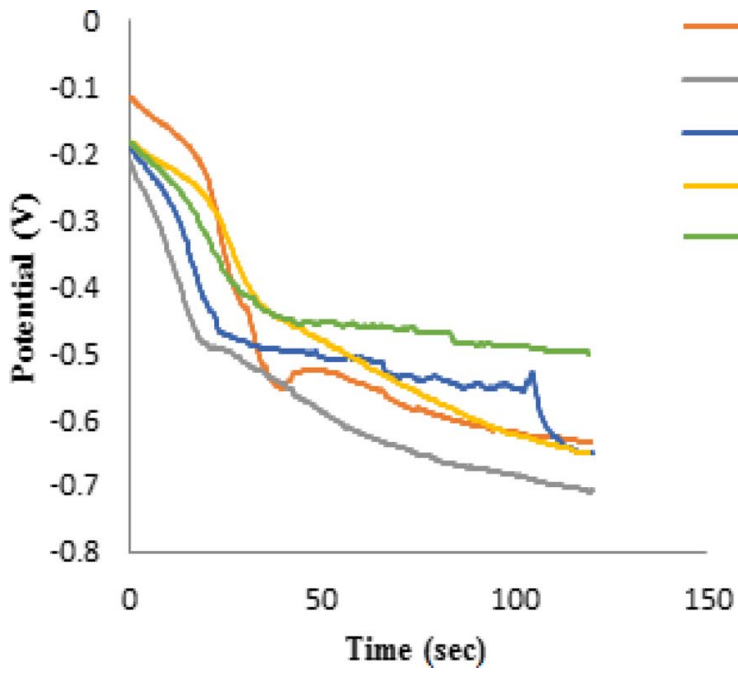

AA6061+8\%RHA + Clay@75 $\mu \mathrm{m}$ AA6061

-AA6061+2\%RHA+Clay@150um

-A.A6061+2\%RHA+Clay@75 $\mu \mathrm{m}$

-AA 6061+8\%RHA+Clay@150um

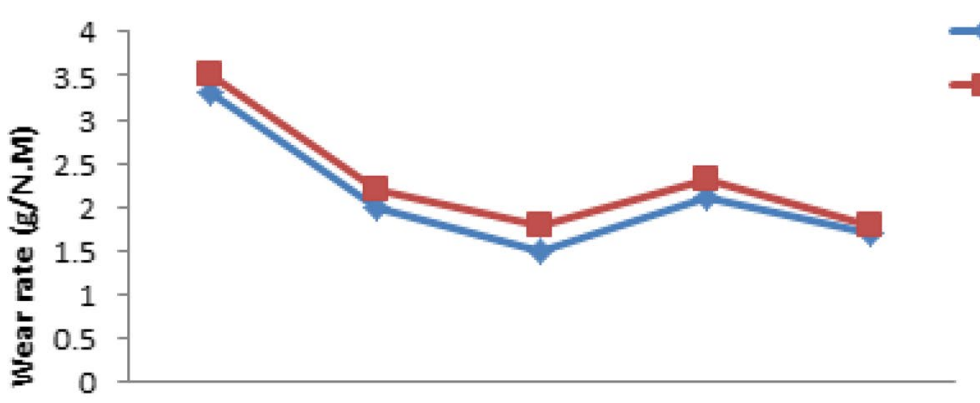

- load at $7.5 \mathrm{~N}$

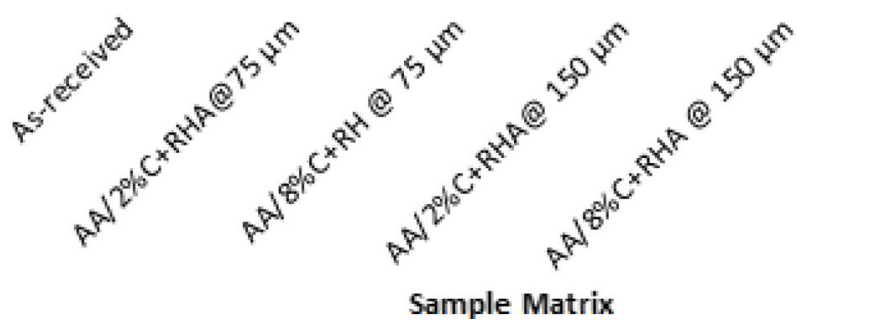

resistance of the material. The wear rate of the control sample increases slightly under the wear counter load in the absence of the particulate. This enhancement in the wear resistance is attributed to the particulate causing superior strengthening effect and load-bearing capacity that is capable of retarding and making resilient deformation under plastic application.

Figure 11 shows the variation in the coefficient of friction with $7.5 \mathrm{~N}$ and $10 \mathrm{~N}$ loads from the AA6061/RHA + clay alloy series against the as-received sample at $75 \mu \mathrm{m}$ and $150 \mu \mathrm{m}$ grain size fabricated reinforcements. Higher coefficient of friction was experienced by the as-received samples as against the developed particulate alloy. From all indications, it can be seen that AA6061/8\% RHA + clay matrix at load of $7.5 \mathrm{~N}$ displayed a lesser friction coefficient against the starting materials as the load progresses. Although, it was confirmed that the reduction in the coefficient of friction is often attributed to the presence of pool of anti-wear particulate participating between the alloy boundary preventing and mostly allowing slight frictional loss during services [18].

It is evidently that the filler embedded reduces the coefficient of friction characteristics of the aluminium metal matrix series, thereby providing suitable edged against the control samples. In all, a decrease in the coefficient of friction is a sign of an improved nature of the reinforced hybrid alloy [19].

\subsection{Potentiodynamic Polarization Measurements}

The corrosion properties of developed AA6061/ RHA + clay composite were investigated in $0.75 \mathrm{M} \mathrm{H}_{2} \mathrm{SO}_{4}$ environments using potentiodynamic polarization route. The tafel extrapolated value revealing corrosion potential (Ecorr), corrosion current density (jcorr), corrosion rate (CR) and polarization resistance (RP) is shown in Table 2 
Fig. 11 Graph of wear friction coefficient against load
Table 2 Potentiodynamic polarization results (AA6061/ clay + $\mathrm{RHA}$ in $\mathrm{H}_{2} \mathrm{SO}_{4}$ solution)

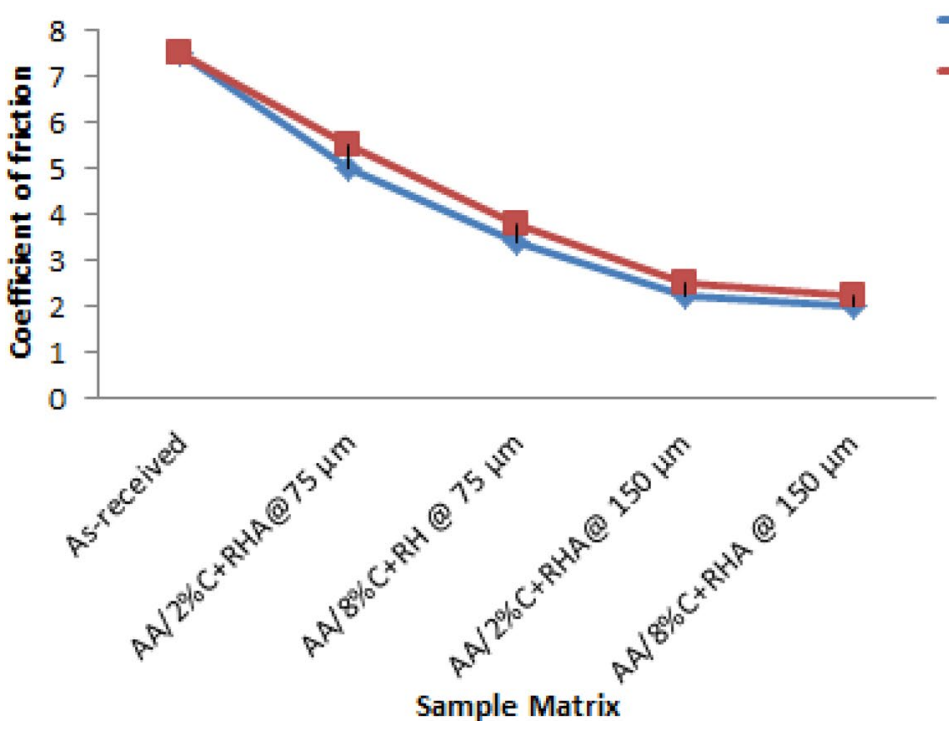

- Load at $7.5 \mathrm{~N}$ Load at $10 \mathrm{~N}$

\begin{tabular}{llllll}
\hline Sample & $E_{\text {corr }}(\mathrm{V})$ & $j_{\text {corr }}\left(\mathrm{A} / \mathrm{cm}^{2}\right)$ & $\begin{array}{l}\text { Corrosion rate } \\
(\mathrm{mm} / \text { year })\end{array}$ & $R_{\mathrm{p}}(\Omega)$ & $\begin{array}{l}\text { Particle } \\
\text { size } \\
(\mu \mathrm{m})\end{array}$ \\
\hline As-received & -0.72218 & $1.28 \times 10^{-4}$ & 1.4869 & 249.79 & - \\
AA6061 + 2\% C+RH & -0.65118 & $1.04 \times 10^{-4}$ & 1.2199 & 371.83 & 75 \\
AA6061 + 8\% C+RH & -0.62825 & $5.17 \times 10^{-5}$ & 0.60159 & 508.07 & 75 \\
AA6061 + 2\% C+RH & -0.70882 & $7.02 \times 10^{-5}$ & 0.81673 & 270.84 & 150 \\
AA6061 + 8\% C+RH & -0.71588 & $1.22 \times 10^{-4}$ & 1.3623 & 251.27 & 150 \\
\hline
\end{tabular}

Fig. 12 Potentiodynamic polarization curves for AA6061/ clay + RHA at $\mathrm{H}_{2} \mathrm{SO}_{4}$

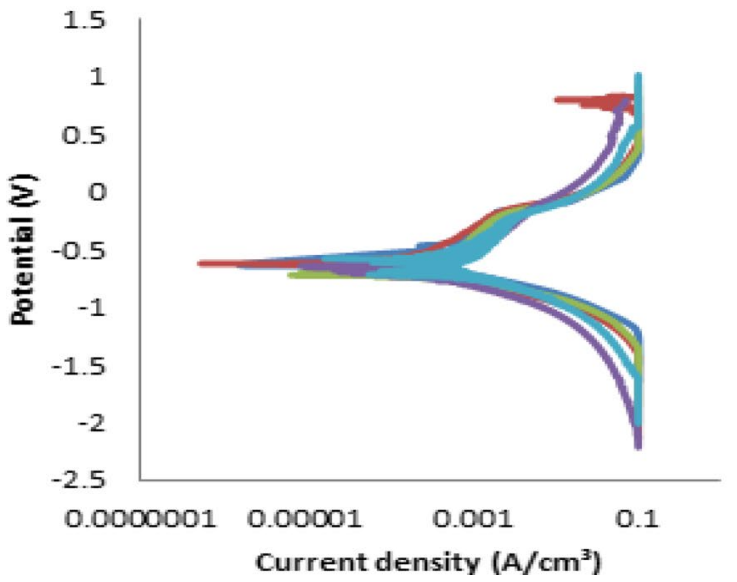

and Fig. 12. Table 2 shows that AA6061/8\% RHA + clay at $75 \mu \mathrm{m}$ possesses the most corrosion resistance behaviour with minimal corrosion rate. Certainly, the corrosion rate of $0.60159 \mathrm{~mm} /$ year was attained compared to $1.4869 \mathrm{~mm} /$ year of the control as-cast aluminium alloy. No doubt, the developed composite with inter-grain presence possesses better corrosion propagation in this order AA6061/8\% clay + RHA at $75 \mu \mathrm{m}$, AA6061 + 2\% clay + RHA at
$75 \mu \mathrm{m}, \mathrm{AA} 6061+2 \% \mathrm{C}+\mathrm{RHA}$ at $150 \mu \mathrm{m}, \mathrm{AA} 6061+8 \%$ $\mathrm{C}+\mathrm{RHA}$ at $150 \mu \mathrm{m}$ and as-received alloy. It is clear that particulate inoculated in the aluminium boundary significantly alters the electrochemical responses. More so, the susceptibility action of the agro-based particulate is related to formation of adsorptive barrier required for retarding corrosion initiation. Noticeably, the particulate adsorption of the Al-interface blocks the active vacancies 
that could promote the rate of corrosion in service as presumed by [20].

\section{Conclusions}

The following conclusions were made:

AA6061/rice husk ash + clay composite through stir casting techniques shows a substantial improvement on the produced material.

AA6061/rice husk ash + clay at $75 \mu$ m yielded the optimal value when compared with the starting materials in all performance evaluations.

It was obvious that the use of RHA and clay enhances corrosion resistance of the composites in $0.75 \mathrm{M} \mathrm{H}_{2} \mathrm{SO}_{4}$ solution.

Finally, SEM structure shows accumulation of distributed grains and dense crystalline structure in comparison with as-received sample.

Acknowledgements The author acknowledges Covenant University for the financial support offered for the publication of this research.

\section{References}

1. Alaneme KK, Adewale TM, Olubambi PA (2014) Corrosion and wear behaviour of $\mathrm{Al}-\mathrm{Mg}-\mathrm{Si}$ alloy matrix hybrid composites reinforced with rice husk ash and silicon carbide. J Mater Res Technol 3(1):9-16

2. Prasad DS, Krishna AR (2010) Fabrication and characterization of AA356.2-Rice husk ash composite using stir casting technique. Int J Eng Sci Technol 2(12):7603-7608

3. Narasaraju G, Raju DL (2015) Characterization of hybrid rice husk and fly ash-reinforced aluminium alloy $\left(\mathrm{AlSi}_{10} \mathrm{Mg}\right)$ composites. Mater Today Proc 2:3056-3064

4. Kumar BA, Murugan N (2012) Metallurgical and mechanical characterization of stir cast AA6061-T6-AlNp composite. Mater Des 40:52-58

5. Fayomi OSI, Joseph OO, Akande IG, Ohiri CK, Enechi KO, Udoye NE (2019) Effect of CCBP doping on the multifunctional Al-0.5 Mg-15CCBP superalloy using liquid metallurgy process for advanced application. J Alloys Compd 783:246-255

6. Apasi A, Yawas DS, Abdulkareem S, Kolawole MY (2016) Improving mechanical properties of aluminium alloy through addition of coconut shell-ash. J Sci Technol 36(3):34-43
7. Daniyan AA, Umoru LE, Popoola API, Fayomi OSI (2017) Comparative studies of microstructural, tribological and corrosion properties of $\mathrm{Zn}-\mathrm{TiO} 2$ and $\mathrm{Zn}-\mathrm{TiO} 2-\mathrm{WO} 3$ nano-composite coatings. Results Phys 7:3222-3229

8. Fayomi OSI, Popoola API, Kanyane LR, Monyai T (2017) Devel-

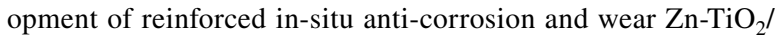
$\mathrm{ZnTiB}_{2}$ coatings on mild steel. Results Phys 7:644-650

9. Alaneme KK, Sanusi KO (2015) Microstructural characteristics, mechanical and wear behaviour of aluminium matrix hybrid composites reinforced with alumina, rice husk ash and graphite. Eng Sci Technol 18:416-422

10. Aigbodion VS (2007) Particulate-strengthened of Al-Si alloy/ alumino-silicate composite. Mater Sci Eng 460-461:574-578

11. Ahamed S, Budan DA, Hemanth J (2014) Wear behaviour of chilled aluminium alloy- Kaolinite/Carbon hybrid metal matrix composite. Int J Emerg Technol Adv Eng 4(7):609-615

12. Kushwaha TN (2017) Fatigue failure analysis of a cooling fan blade: a case study. Int O M Conf 6:717-726

13. Udoye NE, Fayomi OSI, Inegbenebor AO (2019) Review on performance of existing cooling tower fan blade in the production industry. Int J Mech Eng Technol 10(01):1833-1839

14. Ramachandra M, Radhakrishna K (2006) Sliding wear, slurry erosive wear, and corrosive wear of aluminium $/ \mathrm{SiC}$ composite. Mater Sci 24(2): 1

15. Abdulwahab M, Madugu IA, Yaro SA, Hassan SB (2011) Effects of multiple-step thermal ageing treatment on the hardness characteristics of AA356.0-type Al-Si-Mg alloy. Mater Des 32(3):1159-1166

16. Agbeleye AA, Esezobor DE, Balogun SA, Agunsoye JO, Solis J, Neville A (2017) Tribological properties of aluminium-clay composites for brake disc rotor applications. J King Saud Univ. https://doi.org/10.1016/j.jksus.2017.09.002

17. Gupta V, Takhi S (2015) Effects of rice husk ash particulates on the mechanical and tribological properties of the aluminum metal composite reinforced with aluminum oxide. Int J Sci Res Dev 3(3)

18. Sozhamannan GG, Yusuf MM, Aravind G, Kumaresan G, Velmurugan K, Venkatachalapathy VSK (2018) Effect of applied load on the wear performance of AA60611/Nano Ticp/Gr hybrid composites. Mater Today 5:6489-6496

19. Ochieze BQ, Nwobi-Okoye CC, Atamuo PN (2018) Experimental study of the effect of wear parameters on the wear behavior of AA356 alloy/cow horn particulate composites. J Homepage $1: 77-82$

20. Kgoete FM, Popoola API, Fayomi OSI (2018) Influence of spark plasma sintering on microstructure and corrosion behaviour of Ti-6Al-4V alloy reinforced with micron-sized $\mathrm{Si}_{3} \mathrm{~N}_{4}$ powder. Defence Technol 14:403-407

Publisher's Note Springer Nature remains neutral with regard to jurisdictional claims in published maps and institutional affiliations. 